\title{
PERCEPTIONS OF THE LOCKDOWN: CURRENT AND RETROSPECTIVE ASSESSMENTS
}

\author{
Marina Egorova $^{1}$, Oxana Parshikova ${ }^{1}$, Daria Tkachenko ${ }^{2}, \&$ Yulia Chertkova ${ }^{1}$ \\ ${ }^{1}$ Lomonosov Moscow State University, Moscow (Russia) \\ ${ }^{2}$ Russian State University for the Humanities, Moscow (Russia)
}

\begin{abstract}
This article presents data from a study conducted over the course of two weeks: the last week of the lockdown and the first week after the lockdown was lifted. The study participants (undergraduate and graduate students, $\mathrm{n}=227$, mean age of $21.8,71.7 \%$ females) rated their perceptions of various aspects of the pandemic (online COVID-19 Questionnaire), as well as the problems that they experienced in the beginning and middle of the lockdown (retrospective assessments) and at the end of the lockdown (current assessments). A brief HEXACO inventory was used to measure personality traits. The results were compared with data obtained in the study conducted during the first three weeks of the lockdown. Its participants (undergraduate and graduate students, $n=617$, mean age of $20.4,74.2 \%$ females) had filled out an online COVID-19 Questionnaire and a brief HEXACO inventory. The objective of the study was to identify changes in the respondents' well-being and behavior during the lockdown, and the role of personality traits in this process.

The main results of the study were as follows: Retrospective assessments of the Danger of COVID-19 and the Fear of Getting Sick relating to the beginning of the lockdown did not contradict the current assessments from that period. The perception that the lockdown brought not only restrictions but also new opportunities dropped sharply between the beginning and the middle of the lockdown and continued decreasing; concurrently, the significance of negative factors increased. Various aspects of disorganization in life were most evident around the middle of the lockdown; disorganization at the end of the lockdown declined, but remained higher than at the start of the lockdown. Perceptions of the Negative Aspects of the Lockdown, Fear of Getting Sick, and Disorganization had a positive correlation with Emotionality and a negative correlation with Conscientiousness at all stages of the lockdown.
\end{abstract}

Keywords: Perception of COVID-19, lockdown, personality traits, HEXACO.

\section{Introduction}

Studies conducted during the COVID-19 epidemic and other less large-scale epidemics of the past two decades show that at least half of respondents experience serious psychological problems: symptoms of depression, heightened anxiety and stress (e.g., Altieri, Santangelo, 2021; Brooks et al., 2020; Casagrande et al., 2020 Gao et al., 2020; Somma et al., 2020; Tung et al., 2020; Qiu et al, 2020). The studies report changes in the relationship between social and biological rhythms (Blume et al., 2020), heightened sensitivity to social risk (Ding et al., 2020), and reduced satisfaction with life (e.g., Brooks et al., 2020; López-Núñez et al., 2021). The results demonstrate an increase on average in psychological problems in the population and are supported by longitudinal studies comparing changes in the psychological status of respondents who were evaluated first before the COVID-19 outbreak and later during the pandemic (e.g., Li S. et al., 2020; Ruggieri et al., 2020; Sønderskov et al., 2020).

Forced isolation, which restricts contacts with the outside world and requires the implementation of new and not always effective distance learning and remote work formats, not only amplifies the psychological stress that sets in as a response to danger and unpredictability, but also exacerbates previously latent problems. This is evidenced, for example, by complications in family relationships and surges in domestic violence observed in different countries (for example, Gelder et al., 2020).

\section{Objectives}

Perceptions of the lockdown and its underlying causes were changing even during the two-week period of isolation. The official lockdown in Russia lasted 67 days, but some restrictions were introduced 
two weeks earlier for students and certain categories of workers when a switch was made to distance learning.

Lengthy isolation is inevitably accompanied by changing attitudes toward the underlying cause of the isolation and toward complying with restrictions, as well as fluctuations in mood and in perception of the self and the surrounding world. The objective of our study was to assess changes in the behavior and well-being of students over the course of the lockdown and to determine the extent to which the reaction to the pandemic and isolation is associated with factor-level traits.

\section{Participants}

Two studies were carried out during the official lockdown in Russia. Study 1 was conducted over the first three weeks of the lockdown. Study 2 was conducted during the last week of the lockdown and the first week after it was lifted. The respondents in both studies were undergraduate and graduate students. The first study had 617 participants with a mean age of $20.4, \mathrm{SD}=2.4,74.2 \%$ females. The second study had 227 participants with a mean age of $21.8, \mathrm{SD}=5.0,71.7 \%$ females.

\section{Measures}

1. The respondents' perceptions of the dangers of COVID-19 and the social situation resulting from the spread of the coronavirus were assessed using a 22-item questionnaire developed by the authors (Egorova et al., 2020). The COVID-19 Questionnaire measures 4 scales: Danger of COVID-19, Conspiracy Beliefs, Recognition of the Need for Quarantine, and Hopelessness.

2. Perceptions of and emotional experiences during the lockdown were diagnosed using a 23-item questionnaire developed by the authors. The respondents were asked to assess the degree to which they experienced particular problems at the beginning, middle, and end of the lockdown. The Problems and Emotional Experiences During the Lockdown Questionnaire measured four scales: Positive Aspects of the Lockdown, Negative Aspects of the Lockdown, Fear of Getting Sick, and Disorganization.

3. A short version of the Russian adaptation of the HEXACO-PI-R inventory (Egorova et al., 2019) was used to assess personality traits: Honesty/Humility, Emotionality, Extraversion, Agreeableness, Conscientiousness, and Openness to Experience.

All of the questionnaires were submitted online. Respondents rated their agreement-disagreement with the statements of three inventories on a 5-point Likert scale.

Study 1 (first three weeks of the lockdown) used the first and third inventory. Study 2 (end of the lockdown) used all three inventories.

\section{Results}

This article presents a brief overview of data obtained in Study 2, which was conducted at the end of the lockdown, and compares some of the results of Study 1 and Study 2.

\subsection{Descriptive statistics}

Mean values from the four scales of the questionnaire obtained in Study 2 (end of the lockdown) are presented in Table 1. Over the course of the lockdown, its positive aspects (such as getting additional free time) became less pronounced, the Fear of Getting Sick decreased, and Disorganization (such as sleep disturbances and increased irritability) escalated, particularly in the middle of the lockdown. Differences between females and males were identified for only one scale: males provided lower assessments of the Negative Aspects of the Lockdown (such as disruption of plans).

Table 1. Mean Values and Standard Deviations of the Problems and Emotional Experiences During the Lockdown Questionnaire Scales.

\begin{tabular}{|l|c|c|c|c|c|c|}
\hline \multirow{2}{*}{$\begin{array}{l}\text { Study } 2 \\
\text { (end of the lockdown) }\end{array}$} & \multicolumn{3}{|c|}{ Lockdown } & \multicolumn{2}{c|}{ End } \\
\cline { 2 - 7 } & \multicolumn{2}{|c|}{ Beginning } & \multicolumn{2}{c|}{ Middle } & & \\
\cline { 2 - 7 } & Females & Males & & & & \\
\hline $\begin{array}{l}\text { Lockdown as New } \\
\text { Opportunities }\end{array}$ & $3.5(1.01)$ & $3.3(1.09)$ & $2.7(1.0)$ & $2.7(1.06)$ & $2.6(1.08)$ & $2.5(0.92)$ \\
\hline $\begin{array}{l}\text { Negative Aspects of the } \\
\text { Lockdown }\end{array}$ & $\mathbf{3 . 1 ( 1 . 0 )}$ & $\mathbf{2 . 5 ( 0 . 9 5 )}$ & $3.2(1.01)$ & $2.7(1.04)$ & $\mathbf{3 . 2 ( 0 . 9 8 )}$ & $\mathbf{2 . 7 ( 1 . 0 )}$ \\
\hline Fear of Getting Sick & $3.4(1.07)$ & $3.3(1.34)$ & $3.1(0.99)$ & $3.1(1.15)$ & $2.6(0.96)$ & $2.8(1.16)$ \\
\hline Disorganization & $2.2(0.90)$ & $2.3(0.81)$ & $2.8(1.03)$ & $2.6(0.98)$ & $2.5(0.98)$ & $2.4(0.88)$ \\
\hline
\end{tabular}

Note: Mean values with significant differences between females and males are marked in bold. 


\subsection{Positive and negative aspects of the lockdown}

When the lockdown was announced, it prompted contradictory emotions. On the one hand, no one was happy about the danger of the coronavirus, the disruption of plans, and the prospects of constantly being in a confined space. On the other hand, the lockdown was associated with a reduced likelihood of infection and the hope that the spread of the epidemic in Russia could be quickly stopped. Against this complex emotional background, the sudden and extreme nature of the developments was perceived by some respondents as a series of exciting events. It is no coincidence that at the start of the lockdown, the tendency to see its positive aspects exhibited a positive correlation with Emotionality $(\mathrm{r}=0.19, \mathrm{p}<0.01)$. Fifty-nine percent of respondents recalled that when the lockdown was announced, they were almost exhilarated by the extraordinariness of the situation. By the middle of the lockdown, the share of such respondents fell considerably to $20 \%$, and by the end of the lockdown it was down to $16 \%$. At the same time, even at the end of the lockdown, the Lockdown as New Opportunities scale showed a negative correlation with the questionnaire item "Forced isolation was harder for me than I thought it would be" $(\mathrm{r}=-.24, \mathrm{p}<.01)$.

By the end of the lockdown, only $16 \%$ of respondents felt that the lockdown gave them an opportunity to relax or to live a less stressful life. Retrospective assessments indicate that about two-thirds $(67 \%)$ of respondents had this expectation at the beginning of the lockdown and less than a third (32\%) did by its middle.

Almost half of respondents believed that they were able to achieve things during the lockdown that they didn't have enough time for previously $(47 \%)$; however, $76 \%$ had hoped for this at the beginning of the lockdown.

Approximately a third of respondents thought at the beginning, middle, and end of the lockdown (34\%, 37\%, and $37 \%$, respectively) that the lockdown and the disruption of normal life was useful for them and helped them understand themselves.

Negative Aspects of the Lockdown became more pronounced as it went on. Respondents found it particularly traumatic that they couldn't interact with friends the way they did before. The percentage of respondents who reported this rose from $30 \%$ at the beginning of the lockdown to $48 \%$ at its end.

At all stages of the lockdown, the tendency to suffer from restrictions resulting from the isolation had a positive correlation with Emotionality $(\mathrm{rs}=0.25,0.34$, and $0.37, \mathrm{p}<0.001)$ and a negative correlation with Conscientiousness ( $\mathrm{rs}=-0.23,-0.18$, and $-0.22,0.01<\mathrm{p}<0.001$ ).

\subsection{Perception of the danger of COVID-19}

The perception of the Danger of COVID-19 was relatively stable (Table 2): indicators from the Danger of COVID-19 scale obtained in the first 3 weeks of the lockdown had a significant correlation with Fear of Getting Sick at the end of the lockdown $(\mathrm{r}=.50, \mathrm{p}<000)$ and with retrospective assessments of the perception of the danger at the beginning $(\mathrm{r}=.50, \mathrm{p}<000)$ and middle $(\mathrm{r}=.52, \mathrm{p}<000)$ of the lockdown. Fear of getting sick and Recognition of the Need for Quarantine remained at approximately the same level.

Belief in Conspiracy Theories and Hopelessness had a negative correlation with the Fear of Getting Sick, i.e., the correlations were analogous to those between these scales and the perception of the Danger of COVID-19 in Study 1 (beginning of the lockdown).

Table 2. Correlations Between Questionnaire Scales Diagnosed During the First Three Weeks of the Lockdown and Fear of Getting Sick Diagnosed at the End of the Lockdown.

\begin{tabular}{|c|c|c|c|c|c|}
\hline \multirow{2}{*}{\multicolumn{2}{|c|}{$\begin{array}{c}\text { Study } 2 \\
\text { (end of the lockdown) }\end{array}$}} & \multicolumn{4}{|c|}{ Study 1 (first three weeks of the lockdown) } \\
\hline & & \multirow{2}{*}{$\begin{array}{r}\text { Danger of } \\
\text { COVID-19 } \\
.50^{* *}\end{array}$} & \multirow{2}{*}{$\begin{array}{l}\begin{array}{l}\text { Belief in } \\
\text { Conspiracy } \\
\text { Theories }\end{array} \\
-.28^{*}\end{array}$} & \multirow{2}{*}{$\begin{array}{l}\text { Recognition } \\
\text { of the Need } \\
\text { for } \\
\text { Quarantine } \\
.46^{* *}\end{array}$} & \multirow{2}{*}{$\begin{array}{c}\text { Hopelessness } \\
-.26^{*}\end{array}$} \\
\hline \multirow{3}{*}{$\begin{array}{l}\text { Fear of Getting } \\
\text { Sick }\end{array}$} & Beginning & & & & \\
\hline & Middle & $.52 * *$ & $-.37 * *$ & $.49^{* *}$ & $-.27^{*}$ \\
\hline & End & $.50^{* *}$ & $-.26^{*}$ & $.54 * *$ & $-.24 *$ \\
\hline
\end{tabular}

The stability of the correlations of the Fear of Getting Sick does not testify to the stability of its absolute values. Over the course of the lockdown, the mean values of the Fear of Getting Sick were declining, as was the share of respondents who perceived the coronavirus as a serious danger. Thus, for example, at the beginning, middle, and end of the lockdown, the share of respondents who were afraid of getting sick amounted to $49 \%, 46 \%$, and $38 \%$, while the share of those who were constantly following the 
dynamics of the pandemic was 54\%, 33\%, and 13\%. Concurrently, the proportion of those who violated lockdown restrictions increased from $28 \%$ to $34 \%$ and then $43 \%$.

It should be noted that the decrease in the subjective assessment of the Danger of COVID-19 by the end of the lockdown did not reflect the actual situation with the pandemic, because the number of new infections in Russia on the day when the lockdown was lifted was much higher than on the day when the lockdown was announced (8,985 on July 8 compared to 771 on April 2). Reasons for the more optimistic view of the pandemic included not only adapting to life with the coronavirus but also quarantine fatigue ("it's better to get the virus than to live like this") and various versions of the devaluation of its dangers, among them unwillingness to hear anything about the coronavirus. Thus, the share of respondents who were paying attention to the dynamics of the pandemic decreased from $54 \%$ at the beginning of the lockdown to $33 \%$ in the middle and $13 \%$ at the end.

Fear of Getting Sick also exhibited a low correlation with Emotionality ( $\mathrm{rs}=.24, .21, .15$, $.05<\mathrm{p}<.001)$ and at the beginning of the lockdown with Extraversion $(\mathrm{r}=-.16, \mathrm{p}<0.02)$, while unwillingness to hear anything about the coronavirus had a negative correlation with Conscientiousness at the end of the lockdown $(\mathrm{r}=-.23 \mathrm{p}<.002)$.

\subsection{Disorganization}

The frequency of positive responses to items related to the Disorganization factor (i.e., statements of ill-being) makes it possible to determine the share of respondents who experienced various problems during the lockdown. The greatest share of positive responses was observed at the middle of the lockdown (up to 53.8\%), when all of the problems of life in a confined space had already become clear, the number of infections continued to rise, and, one after another, forecasts for the lifting of the lockdown were failing to materialize. Between the middle and the end of the lockdown, the percentage of respondents who reported ill-being decreased, but it still remained much higher (by 25-90\%) for all items than it was at the beginning of the lockdown. At the end of the lockdown, respondents most frequently reported that they experienced disruptions in sleep and daily routines, apathy (not wanting to do anything), and a constant sense of tiredness and fatigue, depressed mood, and the feeling that they couldn't think as well (34-51\%).

The Disorganization scale exhibited a correlation with Emotionality at the middle and end of the lockdown ( $\mathrm{rs}=.25, .29, \mathrm{p}<.001$ ), a negative correlation with Agreeableness at the beginning of the lockdown $(\mathrm{r}=-16, \mathrm{p}<0.02)$, and a negative correlation with Conscientiousness at all stages of the lockdown $(\mathrm{r}=-.39,-28,-30, \mathrm{p}<.000)$.

\subsection{Correlations between factor-level personality traits and attitudes toward the COVID-19 pandemic}

The HEXACO personality traits diagnosed in Study 1 (at the beginning of the lockdown) exhibited less close but more varied correlations with various items of perceptions of the pandemic than personality traits diagnosed at the end of the lockdown.

Study 1 showed that the lockdown turned out to be least traumatic for those with high levels of Honesty/Humility, Conscientiousness, and Agreeableness. Extraversion, Feeling of Hopelessness, and Belief in Conspiracy Theories contributed to the violation of lockdown measures. Study 2 found significant correlations with various aspects of experiencing the lockdown for only two personality traits: Emotionality and Conscientiousness.

\section{Conclusions}

The perception that the lockdown generated not only limitations but also new opportunities plummeted between the beginning and the middle of the lockdown, and then continued declining. Concurrently, the significance of negative aspects increased.

The official end of the lockdown did not mean that the problems that had emerged during the period of isolation were resolved. Various aspects of disorganization in life showed through the most at the middle of the lockdown. By the end of the lockdown, Disorganization was declining, although it remained higher than it was at the beginning. At the end of the lockdown, respondents most frequently reported disruptions in sleep and daily routines, apathy (not wanting to do anything), a constant feeling of tiredness and fatigue, depressed mood, and the sense that they could not think as well. The disruptions arising from isolation had the lowest effect on interpersonal relations.

All scales diagnosed during the first three weeks of the lockdown (Danger of COVID-19, Conspiracy Beliefs, Recognition of the Need for Quarantine, and Hopelessness) only exhibited correlation with Fear of Getting Sick at the end of the lockdown. 
The assessment of Negative Aspects of the Lockdown, Fear of Getting Sick, and Disorganization had a positive correlation with Emotionality and a negative correlation with Conscientiousness at all stages of the lockdown.

Retrospective assessments of the Danger of COVID-19 and Fear of Getting Sick did not contradict the current assessments of that period.

\section{References}

Altieri, M., \& Santangelo, G. (2021). The psychological impact of COVID-19 pandemic and lockdown on caregivers of people with dementia. The American Journal of Geriatric Psychiatry, 29 (1), 27-34.

Blume, C., Schmidt, M. H., \& Cajochen, C. (2020). Effects of the COVID-19 lockdown on human sleep and rest-activity rhythms. Current Biology, 30 (14), R795-R797.

Brooks, S.K., Webster, R.K., Smith, L.E., Woodland, L., Wessely, S., Greenberg, N., \& Rubin, G.J. (2020). The psychological impact of quarantine and how to reduce it: rapid review of the evidence. Lancet, 395, 912-920.

Casagrande, M., Favieri, F., Tambelli, R., \& Forte, G. (2020). The enemy who sealed the world: effects quarantine due to the COVID-19 on sleep quality, anxiety, and psychological distress in the Italian population. Sleep Medicine, 75.

Ding, Y, Xu, J, Huang, S, Li, P, Lu, C, \& Xie, S.(2020) Risk perception and depression in public health crises: Evidence from the COVID-19 Crisis in China International Journal of Environmental Research and Public Health, 17(16), 5728.

Egorova, M.S., Parshikova, O.V., \& Mitina, O.V. (2019). Struktura rossiiskogo varianta shestifaktornogo lichnostnogo oprosnika HEXACO-PI-R. [Structure of the Russian variant of the six-factor HEXACO personality inventory]. Voprosy Psikhologii, 5, 33-49.

Egorova, M.S., Parshikova, O.V., Zyryanova, N.M., \& Staroverov, V.M. (2020). Cherti lichnosti i vospriyatie pandemii COVID-19 [Personality traits and the perception of the COVID-19 pandemic]. Voprosy Psikhologii, 4, 81-103.

Gao, W., Ping, S., \& Liu, X. (2020). Gender differences in depression, anxiety, and stress among college students: a longitudinal study from China. Journal of Affective Disorders, 263, 292-300.

Li, S., Wang, Y., Xue, J., Zhao, N., \& Zhu, T. (2020) The Impact of COVID-19 Epidemic Declaration on Psychological Consequences: A Study on Active Weibo Users. International Journal of Environmental Research and Public Health, 17(6), 2032.

López-Núñez, I., Díaz-Morales, J.F., Aparicio-García, M.E. (2021) Individual differences, personality, social, family and work variables on mental health during COVID-19 outbreak in Spain. Personality and Individual Differences, 110562.

Qium J., Shenm B., Zhaom M., Wangm Z., Xiem B., Xum Y. (2020) A nationwide survey of psychological distress among Chinese people in the COVID-19 epidemic: Implications and policy recommendations. General Psychiatry, 33 (2), 100213.

Ruggieri, S., Ingoglia, S., Bonfanti, R.C., \& Lo Coco, G (2020). The role of online social comparison as a protective factor for psychological wellbeing: A longitudinal study during the COVID-19 quarantine. Personality and Individual Differences, 110486.

Somma, A., Gialdi, G., Krueger, R.F., Markon, R.E., Frau, C., Lovallo, S., \& Fossati, A. (2020) Dysfunctional personality features, non-scientifically supported causal beliefs, and emotional problems during the first month of the COVID-19 pandemic in Italy. Personality and Individual Differences, 165, 110139.

Sønderskov, K.M., Dinesen, P.T., Santini, Z.I., \& Østergaard, S.D. (2020) The depressive state of Denmark during the COVID-19 pandemic. Acta Neuropsychiatrica, 1-3.

Tang W., Hum T., Hum B, Jinm C., Wangm G., Xiem C., Chenm S., \& Xum J. (2020). Prevalence and correlates of PTSD and depressive symptoms one month after the outbreak of the COVID-19 epidemic in a sample of homequarantined Chinese university students. Journal of Affective Disorders, 274, 1-7.

Van Gelder, N., Peterman, A., Potts, A., O'Donnell, M., Thompson, K., Shah, N., \& Oertelt-Prigione, S. (2020). COVID-19: Reducing the risk of infection might increase the risk of intimate partner violence. EClinicalMedicine, 21. 